Educación Física y Ciencia, vol. 19, n 1, e018, junio 2017. ISSN 2314-2561

Universidad Nacional de La Plata.

Facultad de Humanidades y Ciencias de la Educación.

Departamento de Educación Física

\title{
En torno a los orígenes del fútbol como deporte escolar en España (1883-1936). De moda recreativa a dispositivo disciplinario
}

\author{
On the origins of football as a school sport in Spain (1883-1936). \\ From a recreational trend to a disciplinary instrument
}

\section{Xavier Torrebadella Flix *; Miguel Vicente Pedraz **}

*Universidad Autónoma de Barcelona, España; ** Universidad de León, España | xtorreba@gmail.com ; mvicp@unileon.es

\section{PALABRAS CLAVE}

Historia del fútbol

Fútbol escolar

Educación física

Dispositivo disciplinar

\section{KEYWORDS}

History of football

School football

Physical education

Disciplinary instrument

\section{RESUMEN}

Este artículo aborda el proceso de configuración del fútbol como deporte de masas en el entorno social, político e ideológico de finales del siglo XIX y principios del XX. Con una perspectiva genealógica describe y analiza el papel que ejerció el fútbol infantil en el desarrollo y legitimación de la práctica balompédica más allá de los muros escolares. Una lectura crítica de las fuentes documentales presentadas permite constatar que, en gran medida, la entronización del fútbol y su pronta hegemonía en el contexto del deporte español tuvo como gran valedor ideológico el discurso regeneracionista finisecular y como mejor apoyo político-administrativo al propio Estado. Este, a través del asociacionismo deportivo, los clubes juveniles parroquiales o laicos, la educación física escolar, y también a través de políticas de ordenación urbana, supo canalizar la capacidad de convocatoria del fútbol para hacer de él un eficaz aparato de disciplinamiento y control. 


\section{Introducción}

La práctica deportiva social y la práctica deportiva escolar han mantenido desde sus comienzos, a mediados del siglo XIX, una íntima relación; si bien, no una relación lineal y unidireccional, de fuera adentro. Es decir, contra lo que tiende a pensarse, la escuela no es siempre un mero receptáculo en el que se reproducen las prácticas deportivas sociales dominantes, sino que en ocasiones, son las prácticas originadas en el entorno escolar las que, mediante un proceso de difusión -no exento de transformaciones técnicas, ideológicas, organizativas, etc.-, acaban por imponerse en algunos, a veces muy amplios, ámbitos sociales y culturales. Deportes como el baloncesto o el voleibol aparecen en la historiografía del deporte como paradigmáticos de este movimiento, de dentro afuera; el mismo sentido se aprecia en la mayor parte de las pruebas atléticas, las cuales, según Mandell (1986) fueron inventadas y estandarizadas por estudiantes universitarios ingleses. Mucho menos común es considerar en este grupo de deportes el fútbol cuyo origen suele relacionarse con prácticas festivas medievales (Salvador, 2004), ulteriormente evolucionadas y reglamentadas ${ }^{1}$. Particularmente, la historiografía del fútbol español ha presentado este deporte vinculado al asociacionismo deportivo sin apenas profundizar en sus raíces escolares ni en la importancia que en su asentamiento y desarrollo tuvieron los discursos pedagógicos; unos discursos que desde finales del XIX, aunque con cierta desconfianza inicial, enfatizaron sus virtudes morales y, en general, educativas.

Desde luego, no cabe duda de que la fundación de pequeñas asociaciones y clubes de fútbol por parte de empresarios y trabajadores ingleses afincados en zonas de explotación minera o industrial fue un detonante y tal vez una condición necesaria de su popularización; pero sería ingenuo pensar -como a veces se ha sostenido- en el solo deseo de los lugareños de emular las pericias balompédicas y el estilo de vida de aquellos pioneros como factor único de su rápido arraigo en la sociedad española. Tanto la invención del fútbol como su posterior desarrollo, popularización y expansión geográfica fue, de acuerdo con Elias \& Dunning (1992) o Mandell (1986), el resultado una multiplicidad de factores socioculturales, ideológicos, económicos y políticos cuya concurrencia, a finales del XIX y principios del XX, propició la conversión del fútbol en el fenómeno de masas que hoy conocemos.

Pues bien, de entre todos los factores, algunos de ellos relativamente bien estudiados, en este artículo pretendemos poner de relieve la importancia del movimiento de difusión del futbol de dentro afuera, de la escuela a la sociedad, de práctica escolar recreativa, higiénica y educativa a práctica social; un movimiento de difusión en el que el juego sufriría los correspondientes procesos de transformación tanto práctica como simbólica (de significados) y en cuya legitimación jugaría un papel fundamental su idoneidad para operar como dispositivo disciplinario; su idoneidad para operar, incluso, como dispositivo anticontestatario (Vicente, 2005).

A este respecto, nuestro propósito particular es, a partir de la localización, análisis y cotejo de las fuentes primarias más relevantes, la descripción e interpretación del proceso de conformación del fútbol escolar (primera y segunda enseñanza) en España en el entorno de 1883 y hasta 1936, coincidiendo con el comienzo de la guerra civil. Tomamos 1883 como punto de partida simbólico por ser el año en que aparece la primera noticia del juego del fútbol entre los alumnos de la emblemática Institución Libre de Enseñanza (ILE) en Madrid.

Para la localización las fuentes documentales primarias hemos partido de El repertorio bibliográfico inédito de la educación física y el deporte en España (Torrebadella, 2011b) cuya lectura científica ha permitido desarrollar la parte heurística de la investigación. Dicho repertorio se ha completado con un vaciado de noticias de las bases de datos de la Hemeroteca Digital de la Biblioteca Nacional, la Biblioteca Virtual de la Prensa Histórica, el Arxiu de Revistes Catalanes Antigues Catalán (ARCA) y la hemeroteca de El Mundo Deportivo. 
La reflexión historiográfica sobre la documentación recogida tiene como punto de anclaje el análisis del discurso (Van Dijk, 2003) y como marco de interpretación, por una parte, la teoría del proceso de la civilización de Elias según la cual la deportivización habría actuado y actúa como mecanismo codificador de la conducta (Eias, 1988) y, por otra, la teoría foucaultiana a propósito de los dispositivos disciplinarios de saber/poder y de la gobernabilidad de las subjetividades (Foucault, 1991).

\section{El deporte como dispositivo ideológico del capitalismo}

De acuerdo con las teorías historiográficas aceptadas en la actualidad, el fútbol tiene su origen en el marco educativo de las elitistas e hiperdisciplinarias Public Schools inglesas de mediados del siglo XIX, coincidiendo con el apogeo desarrollo industrial y colonial de Gran Bretaña. De acuerdo con Harvey (2013), habría sido el reverendo Thomas Arnold quien, al permitir la práctica de los aguerridos juegos corporales a los estudiantes en sus pasatiempos, posibilitó -con el concurso de los cristianos musculares- una especie de modernización del concepto de caballero cristiano -el ideal del gentleman (Almeida, 2003; Corriente \& Montero, 2011; Valserra, 1944)-, cuyos valores se verían reorientados hacia el honor, el coraje, el valor, la fortaleza -la hombría- demostrados en los campos de juego como signos distintivos de la caballerosidad.

Sin el propósito preconcebido de crear una nueva educación basada en el deporte, gracias al éxito de escritos como el Tom Brown de Hughes, que narraba la vida del internado (Almeida, 2003; Barbero, 1990), se popularizó la imagen de una vida escolar centrada en la formación de cualidades deportivas (físicas y morales) hasta el punto de que casi todos los directores de este tipo de establecimientos educativos acabaron consintiendo el deporte, a veces a su pesar, como eficaz medio de control de los estudiantes; particularmente, lo permitieron como forma de canalización de la generalizada violencia en la que se desarrollaba el día a día de la escuela.

Estaba naciendo el deporte contemporáneo que, en pocos años, se convertiría si no en "la piedra angular del Imperio Británico”, que decía Valserra (1944, 249), sí en un importante mecanismo de colonización cultural e ideológica (Mandell, 1986). Deportes como el criquet, el foot-ball rugby y, en especial, el foot-ball association se convirtieron en potentes embajadores del estilo de vida británico por todo el mundo: un renovado estilo de vida victoriano que, como sello de distinción, se imponía sobre los modos y maneras propios del resto de las naciones.

De esta modalidad de ejercicio del poder, la educación no sólo no estuvo al margen, sino que jugaría un importante papel catalizador por el efecto de impregnación y difusión que esta ejercía en el entorno próximo a través de los escolares. Según Elias y Dunning (1992) o Mandell (1986), desde muy pronto muchos de los principales colegios de Europa adoptaron los rasgos del sistema educativo de las Public Schools a cuya legitimación contribuyó, sin duda, la propaganda olímpica del autoproclamado sucesor de Arnold, el barón Pierre de Coubertin.

En España, la llegada del fútbol sucitó en una doble interpretación. Mientras que muchos lo vieron como una moda inglesa que habría de pasar tan rápido como había llegado, otros, en cambio, encontraron en él un medio de regeneración que podía coadyuvar a la educación física y moral de la maltrecha juventud española (González-Aja, 2011; Torrebadella, 2012d, 2014c). En cualquier caso, la indiscutible relación entre deporte, en especial el fútbol, y el movimiento regeneracionista (McFarland, 2008, 2011, Torrebadella, 2014c; Torrebadella-Flix \& Nomdedeu-Rull, 2013, 2015), terminó por auspiciar el movimiento asociativo más importante de la historia; un movimiento cuyo sustrato bio-político -la maquinaria de disciplina que se impone sobre el cuerpo tanto en la esfera privada como en el campo de lo social (Chatziefstathiou \& Henry, 2009; Moraes, 2012; Smith, 2002)- se reveló como una potente forma de (des)movilización ideológica al servicio de los valores y de los intereses del capitalismo industrial. No es casual, a este respecto, la 
confluencia de los valores deportivos y los del espíritu del capitalismo -abnegación, esfuerzo, competencia, máximo rendimiento, jerarquía-, de tal modo que, como dice Jean Marie Brohm 1993, 48), "la constitución del deporte mundial corre paralelo a la consolidación del imperialismo".

\section{La introducción del fútbol escolar en España}

Antes de la irrupción del fútbol, los jóvenes españoles se recreaban con el popular juego del marro, un desafío estratégico de persecución entre dos bandos que, aunque se jugase sin un balón, tenía aspectos en común con el fútbol (Brasó \& Torrebadella, 2014; Torrebadella \& Brasó, 2015). El fútbol lo fue desplazando a un segundo término -junto a otros muchos juegos populares y tradicionales masculinos- hasta convertirse en "el primer juego colectivo de oposición-colaboración que en España se consagró como deporte, tal y como hoy lo entendemos” (Torrebadella, 2014a, 74).

Entre las causas que hicieron que el fútbol adquiriese tanta popularidad no es menor su pronta penetración en los ambientes educativos a través de las escuelas más elitistas del momento. Como indicó Antonio Viada (1903), el fútbol fue introducido en España por algunos colegios que trataban de imitar a los colegios extranjeros; entre ellos, no pocos pertenecían a congregaciones religiosas como el colegio de San Albano en Valladolid a finales del siglo XIX (Ortega, 1996), los colegios jesuitas de Orduña en Bilbao (Turuzeta, 2012) o El Salvador de Zaragoza (Ciria, 2013). También se puede constatar su práctica, según Torrebadella (2012), en algunos de los Institutos de segunda enseñanza. En todo caso, la presencia del fútbol en España como sport escolar tiene sus prolegómenos en la ILE cuando, hacia 1883, el profesor Stuart Hembest Capper enseñó a jugar el entonces llamado foot-ball, a los escolares de Madrid (Bahamonde, 2002; López Serra, 1998; Torrebadella, 2012d); justo en el periodo fundacional de la educación física escolar en la que confluyeron los temores finiseculares de la degeneración moral y física y el propósito liberal de regeneración, y que la Escuela Central de Gimnástica (1887-1892), en su corta existencia, trató de catalizar.

En la ILE entroncaron las influencias del modelo educativo inglés y alemán (Fernández-Soria, 2014). Por un lado, Arnold y Spencer le aportaban el elitismo del self government, que caracterizaba el sportsmen; y, por otro, el krausismo le confería el idealismo del "hombre nuevo" que buscaban los institucionalistas. En este contexto, el fútbol se reveló como una práctica que permitía aplicar el modelo pedagógico de Giner de los Ríos a la mediana burguesía. A través del Museo Pedagógico Nacional, la ILE desplegó su proyecto de reforma educativa para la primera y segunda enseñanza donde se reconocían los modelos inglés, alemán y francés, los cuales disponían de "campos de juego de las grandes ciudades abiertos diariamente á los niños de las Escuelas con sus Profesores” (Museo Pedagógico Nacional, 1895, 118). Este diligente interés hacia el juego corporal, aunque también hacia la restitución de los antiguos juegos tradicionales locales, es lo que demandaban pública y oficialmente los representantes de la ILE (Giner, 1884, 1887). Su influencia llegaría a la Dirección General de Instrucción Pública que, por mediación de Eduardo Vincenti, normativizó las líneas pedagógicas de la educación física para los Institutos de Segunda Enseñanza:

Al lado de la gimnástica sueca, de carácter esencialmente pedagógico, hay en la actualidad otro gran movimiento que influye poderosamente también para transformar la educación física en todos los países: el de los juegos corporales al aire libre y en pleno campo, cultivados con indecible entusiasmo por el pueblo inglés, y que ha hecho de su juventud la más sana y vigorosa de nuestro tiempo (Pedregal, 1895, 148).

La cuestión alcanzó cierta relevancia social aunque cada cual la gestionó según sus propias preocupaciones. Por ejemplo, Antonio Benítez de Lugo, marqués de Santa Susana, desde las páginas de Crónica del Sport rendía culto al deporte anglosajón y aconsejaba incorporar el foot-ball en España, para contribuir a una educación de la juventud. Apuntaba que "todos nos quejamos de la falta de asociación que hay en nuestro 
país, de la inclinación á la desobediencia á personas ó leyes y del poco respeto de unos hacia otros; somos, pues, en todo, individualistas” (Benítez, 1896, 7). Pedro de Alcántara García (1898, 6), alma ideológica del magisterio español de la época, consideró el fútbol idóneo para servir a "la campaña que es urgentísimo emprender en favor de la regeneración física de nuestro pueblo, que por muchos estilos necesita de toda necesidad la aplicación práctica del tan justamente recordado aforismo de Juvenal; Mens sana in corpore sano".

Lógicamente, los primeros torneos infantiles -escolares- tuvieron lugar en grandes ciudades como Barcelona, Madrid, Bilbao, Valencia o Sevilla donde, por diversas razones, el fútbol encontró mejores condiciones para arraigar (Torrebadella \& Nomdedeu, 2015). Por ejemplo, en Barcelona donde la promoción del fútbol escolar fue acometida por la Federación Gimnástica Española (FGE), los torneos escolares alcanzaron un importante grado de institucionalización y fueron muchos los colegios y clubes deportivos que muy pronto se entregaron al nuevo deporte colectivo (Barba, 1912; Viada, 1903). La primera escuela de fútbol, propiamente dicha, se creó en 1902; se trataba de la escuela del Futbol Club Barcelona para la formación de los hijos de los socios dirigida por Udo Steinberg. Entre los primeros campeonatos infantiles destacan, ya en 1903, los celebrados en Madrid y en Bilbao (Torrebadella, 2012d).

Como planteábamos en la introducción, en la formación del caldo de cultivo para que el fútbol se desarrollara como deporte de masas contribuyó de manera determinante el proceso de industrialización liderado por empresas británicas. El crecimiento industrial de finales de siglo actuó como motor de la economía liberal y subsidiariamente de los grandes flujos migratorios desde la España interior y agraria hacia las populosas zonas industriales (Bahamonde, 2011; Domínguez, 2011; Torrebadella \& Nomdedeu, 2015); zonas donde las desigualdades sociales se agrandaban y, sobre todo, se hacían más evidentes dando lugar a un escenario de conflictividad obrera que se recrudeció con la crisis del '98. En ese contexto, el fútbol se reveló como un dispositivo de canalización de las tensiones sociales; particularmente, el fútbol escolar actuó mecanismo disuasorio ante la reivindicación de políticas sociales, higiénicas y de protección de la infancia en pleno auge del regeneracionismo (Quintanas, 2011). A este respecto, la reducción de la morbilidad y la mortalidad infantil, a menudo derivados del vagabundeo, la mendicidad y la delincuencia en la que se hallaba una buena parte de los menores constituyó uno de los principales focos de atención de médicos, higienistas, pedagogos, militares o eclesiásticos (Varela \& Álvarez-Uría, 1991) cuyas propuestas incluían, no sin reservas, gimnasia, recreo o deporte, además de la escolarización -o como parte de ella-, en la lucha por la definición de la infancia y su control.

Del elenco de iniciativas institucionalistas cabe destacar la promulgación de la Ley de Educación de 1901 que imponía la escolaridad obligatoria hasta los doce años. Aunque la iniciativa respondía a las demandas regeneracionistas, es decir, como la solución al controvertido "problema nacional” (Delgado, 1997), con ella, el Estado benefactor encontró un inestimable mecanismo de reclutamiento y tutela de la infancia (Calvo, 2012; Fernández Enguita, 1990; Varela, 1983; Varela \& Álvarez-Uría, 1991) que ayudó a establecer el orden público y a garantizar la seguridad general (Solana, ca. 1909); a la vez, aseguraba unos mínimos de disciplina a quienes habrían de ser muy pronto obreros o soldados. En todo caso, al logro de la normativización y disciplina contribuyeron algunas otras las leyes como la de protección a la infancia y diversas medidas asistenciales lideradas por el tercer sector (colonias escolares, escuelas-taller, cantinas escolares, escuelas-reformatorio, asilos de infancia, etc.).

Por otra parte, en un ambiente de poderosa anglofilia, las modas llegadas de Gran Bretaña eran acogidas siempre con entusiasmo por la mediana y la alta burguesía (Fernández-Soria, 2014), en una atávica competición depredadora (Veblen, 2008) para acaparar los rasgos de las distinguidas élites anglosajonas erigidas en patrón de supremacía (Demolins, 1899). Pero este juego de apariencias y de poder representaba a la vez un nuevo escenario de oportunidades económicas, sobre todo, a través de la mercantilización del ocio 
deportivo (Pujadas \& Santacana, 2001) cuya iconografía representaba perfectamente el modelo social británico.

Fue en este contexto donde los promotores del fútbol fraguaron sus discursos y los hicieron recurrentemente públicos en la prensa (Álvarez-Santullano, 1903; Zulueta, 1903); particularmente, fueron frecuentes las soflamas, dirigidas a la "aristocrática” juventud burguesa escolarizada en la enseñanza superior, la cual se hizo partícipe de la demanda de terrenos aptos para la práctica de los juegos corporales. Esta demanda, que coincidiría con el proceso de reordenación urbana en respuesta a las peligrosas aglomeraciones de los suburbios, fue vista, antes que como un problema de orden y descontento, como una oportunidad para llevar a cabo una agresiva política de profilaxis social; sobre todo para abrir espacios en medio de la ciudad que, con la justificación de dar solaz al pueblo permitiendo jugar al foot-ball association (Climent, 1901; Elias, 1903; Ferrer, 1901; García, 1902, 1903), fue disolviendo el intrincado espacio urbano, haciéndolo cada vez más transparente al ojo del poder. No pasaría mucho tiempo desde que el fútbol alcanzara carta de naturaleza en las principales ciudades españolas, hasta que la población infantil incurriera en la apropiación de espacios -intra y extra muros de la escuela- para practicar el nuevo deporte.

A dicha apropiación contribuyeron algunos destacados portavoces y propagandistas de la educación física como Federico Climent quien aconsejaba el uso del fútbol "para disciplinar el espíritu y acostumbrarlo a la obediencia, sin menoscabo de la libertad individual” (Climent, 1904, 55).

El andamiaje social y empresarial del que gozaban las grandes ciudades como Barcelona fue un elemento determinante del desarrollo del tejido asociativo que supondría un impulso definitivo al proceso de deportivización (Torrebadella, 2012c, 2012d). Pero en dicho impulso jugaría un papel primordial la acogida que el fútbol tuvo en los ambientes escolares de los colegios más elitistas de Barcelona. Estos, ubicados generalmente en las afueras de la ciudad, disponían de espacios suficientes para instalar sus propios campos de juego y practicarlo en óptimas condiciones. Practicarlo de ese modo confería una pátina "aristocrática" solo al alcance los jóvenes de "casa buena”; sin embargo, el juego era practicado de modo informal en casi todos los rincones de Barcelona (Corredissas, 1902; Elias, 1901, 1903). En la revista Intimidades podía leerse: "La afición ha cundido de tal modo, que todo el mundo juega ya á futbol... ¡es tan fácil cosa esa de lanzarse la pelota! Nuestra juventud, la que puede, acapara todos los balones de El Siglo, y la que no, juega con piedras, con cajas de cartón, con lo que sea factible de empujarse con los pies é introducirse en el goal" (Intimidades, 1903, 134).

Los clubes deportivos fueron los impulsores de los primeros campeonatos de fútbol infantil y la prensa daba noticia de los eventos. En 1906 se organizó el Campeonato de Fútbol Infantil de Guipúzcoa y en Vigo la “Copa Rodrigo Alonso” (Ocaña, 1906; Sena, 1906).

En 1907, Alberto Serra, redactor deportivo de La Vanguardia -Barcelona-, pretendía acercar el fútbol a los jóvenes, pero advertía que todavía no se practicaba con el grado de deportividad que caracterizaba el juego en los equipos amateurs de Inglaterra, Francia, Alemania o Italia. Serra convenía en defender que el nuevo deporte era "una lucha sana y violenta" y que los "raros golpes que podían recibirse accidentalmente entre los jóvenes cortesanos y bien educados sirven más bien para templar el cuerpo y el alma del atleta quien pone en juego en él todas las partes del organismo” (Serra, 1907, 151-152). Argumentaba que la destreza del fútbol equivalía a la organización y similitud con el ajedrez, juego que desarrolla una forma matemática y académica de lucha: "Debemos pues inclinar a nuestros adolescentes que por las condiciones físicas de la raza han demostrado que son perfectamente aptos para este juego, hacia las prácticas de asociación, pero bajo la dirección al principio del maestro getlemen” (Serra, 1907, 152).

Al margen de Barcelona, en otras poblaciones fueron los profesores de educación física en los institutos de segunda enseñanza los que frecuentemente se ocuparon de dimensionar la emergencia del fútbol escolar. Son 
ejemplos, los profesores David Ferrer en Barcelona, Luciano Sampérez en Badajoz, Salvador López en Sevilla, Francisco Medel en Murcia o Manuel de Salas en Lérida (Castro, 2012; Medel, 1903; Rebollo, 2009; Rodríguez, 1919; Torrebadella, 2012d). Estos profesores, algunos catedráticos de gimnástica, y entusiastas “apóstoles de la educación física” en su territorio (Torrebadella, 2014b), estimularon el juego entre los alumnos de los institutos, generalmente de clase media, y en otros colegios privados a los cuales también prestaban servicios educativos.

En 1910 el Fútbol Club Barcelona (FCB) renovó su propia escuela de fútbol infantil dirigida por Hans Gamper (Galí, 1983); hecho que coincidió con la organización del Primer Campeonato Infantil de Fútbol de Cataluña organizado por la Federación Catalana de Clubes de Foot-ball (1910) presidida por Alberto Serra. Paulino Alcántara (1924) citaba que en esta competición ya logró su primer título, entonces con el equipo "Universitary”, unos meses antes de vestir la camiseta del FCB ${ }^{2}$. Este Campeonato de Cataluña fue organizado ininterrumpidamente hasta 1936.

Alejandro Barba (1912) señalaba que la mayoría de los grandes clubes crearon muy pronto sus respectivos equipos infantiles. Podemos considerar que estos equipos eran el ahora llamado 'Futbol Base', es decir el “conjunto de características inferiores al primer equipo de un club” (Nomdedeu, 2009, 83). Así, por ejemplo, en 1913 el Real Club Deportivo Español organizó el Concurso Copa escolar (1913ab), cuyos partidos - a los cuales estaban invitados gratuitamente todos los escolares de Barcelona- se disputaban partidos los jueves por la tarde. Los equipos participantes (en esta primera liga escolar) eran los colegios con alumnos de los cursos 1911-1913: Real Colegio de las Escuelas Pías de San Antonio, Colegio Condal, Real Colegio de Nuestra Señora de las Escuelas Pías, Colegio Cervantes, Colegio Balmes, Academia Politécnica, Instituto General Técnico, Liceo Politécnico y Academia Industrial.

Los equipos infantiles surgían principalmente de los colegios de las congregaciones religiosas donde se concentraban los hijos de las clases pudientes. No obstante, también se institucionalizaron equipos en algunas escuelas de extracción popular y obrera, las cuales se inspiraban en las directrices de la ILE. Una de estas escuelas fue la Institución Integral Armónica que dirigía Max Bembo en Sabadell. Bembo creó allí un equipo llamado "Petits Crusaders" cuya preparación tenía por palenque el campo de Centro de Deportes de Sabadell. El equipo disputó partidos contra otros equipos de Barcelona con el fin de recaudar dinero para la escuela. Así, a beneficio de la obra de Bembo, se realizó en julio de 1913 un importante "Festival Deportivo" consistente en la realización de varios partidos de fútbol, uno de los cuales se jugaba entre los infantiles del Centro de Deportes de Sabadell y los “Petits Crusaders” (Festival deportivo en Sabadell, 1913, 4-5).

Mientras los clubes trataban de involucrar a las corporaciones locales para fomentar su popularidad, los campeonatos infantiles iban tomando carta de naturaleza en todo el territorio. Así sucedió en Bilbao, en donde el propio Ayuntamiento organizó, en 1913, conjuntamente con los clubes de fútbol un Campeonato de fútbol infantil entre las escuelas públicas "favoreciendo así la afición de los niños a la cultura física y los deportes, que son el estímulo del desarrollo de la raza” (Pastor-Ruiz, 2002, 29-30).

\section{Un bio-poder está naciendo}

En el proceso de legitimación del fútbol como práctica escolar es muy interesante analizar, por lo contradictorio que resulta a primera vista, el papel que jugaron quienes ostentaban el monopolio de la moralidad corporal de la infancia, intramuros de las instituciones educativas: los profesores de educación física y la iglesia. Por una parte, cabía esperar una entusiasta acogida por parte del incipiente cuerpo de instructores y profesores de educación física a la vista de las posibilidades higiénicas y pedagógicas que prometía el deporte; por otra, dado el carácter expansivo del fútbol y las controvertidas oportunidades de contacto físico que ofrecía a los jóvenes, el fútbol parecía destinado a recibir toda clase de invectivas por 
parte de una jerarquía eclesiástica aún demasiado atenta a los preceptos tan cristianos como la templanza, el recato y hasta la renuncia. Sin embargo, aunque no se puede decir que hubiera de unanimidad, ni en la profesión físico-educativa el fútbol fue acogido de forma incondicional, ni la Iglesia se pronunció abiertamente contra su práctica; más bien al contrario.

En el ámbito de la educación física, algunas de las voces más autorizadas mostraron sus cautelas ante la rápida proliferación del deporte infantil. Por ejemplo, el profesor de educación física Marcelo Sanz (1913), aunque reconocía las grandes ventajas higiénicas del fútbol, le achacaba un excesivo grado de violencia y, por consiguiente, una infinidad de lesiones a las que se exponían los jugadores; alertaba, sobre todo, a aquellos que no se habían ejercitado previamente en la gimnástica racional. Sanz consideraba el fútbol dentro del grupo de los deportes enérgicos y de tipo atlético, varoniles, apto para los jóvenes, siempre que lo complementaran con otros ejercicios donde actuaran las extremidades superiores. Justamente, esta perspectiva netamente profiláctica del fútbol sería la que, con el tiempo, hiciera que el profesor Sanz se convirtiera en uno de los máximos detractores del fútbol en la escuela y, asimismo, de toda forma de competición por ser contraria a los valores higiénicos que él proclamaba. Incluso llegó a decir que en la escuela los deportes estaban desprovistos de todo valor educativo.

Por su parte, el doctor Alfredo Opisso $(1915,8)$ señalaba que el fútbol, "no es deporte para niños y adolescentes, si no para jóvenes y adultos, por la violencia que exige". Por el contrario, el maestro de educación primaria José Oses consideraba el fútbol como un excelente medio de educación física escolar; en su favor señalaba que en las ciudades de España prácticamente no existía muchacho que no se hubiera apasionado por este deporte, como también en los pueblos gracias a las "elegantes colecciones de cromos que las fábricas de chocolates ponen en manos de los niños, dando a éstos un verdadero curso de foot-ball” (Oses, 1915, 65).

Los reparos higiénicos al fútbol se pusieron de manifiesto en publicaciones tan representativas como Mundo Gráfico:

Es juego demasiado brusco y agitado, demasiado propicio á incidentes peligrosos, para que los pequeños jugadores se entreguen á él sin limitaciones de ningún género. Como se juega entre la juventud no debe jugarse entre niños, para evitar que lo que debe constituir un ejercicio conveniente para el desenvolvimiento físico, se convierta en un pugilato peligroso, en el que pueden sufrir lesiónese lamentar quebrantos de importancia en la salud (Deportes infantiles, 1914, 5).

Por supuesto que muchos profesores de educación física acogieron con agrado la moda del deporte y quisieron ver en él una motivante práctica pedagógica. En Lérida, por ejemplo, el profesor de educación física del Colegio Liceo Escolar, Antonio Sabater, consideraba que el fútbol permitía no solo canalizar la energía, sino que también permitía inculcar los valores, cívicos, higiénicos y morales (Torrebadella, 1999, 2012b). El propio Reglamento Internacional de Foot-ball Asociación indicaba que "no es solamente en la parte física donde influye el viril deporte, si no en la parte moral, pues estimula la energía y disciplina al hombre, siendo para él una escuela de hidalguía y caballerosidad” (Femenía, 1923, 7).

Por lo que se refiere a los directores de la moral católica, aunque con ciertas reservas iniciales, pronto supieron ver en la práctica del fútbol un inestimable instrumento de adoctrinamiento; desde luego, no tardaron en congraciar los principios de la vida recta y abnegada de la que hablaban en los púlpitos con las exigencias de la práctica deportiva. En palabras de Julia Varela (1991), fue precisamente en los colegios elitistas de las grandes ciudades -principalmente de congregaciones religiosas- en donde se produjo la institucionalización del deporte escolar y su pronta difusión. En este sentido, dada la autoridad que la iglesia tenía como salvaguarda de las costumbres, se puede decir que su beneplácito confirió legitimidad al futbol escolar y al deporte en general. 
La primera noticia al respecto data de 1903; la localizamos en el Real Colegio de Alfonso XII de los padres Agustinos de El Escorial, donde el padre Zacarías sistematizó una "Pedagogía aplicada al foot-ball" (GarcíaCandau, 1996, 124); así lo refería Nuevo Mundo:

Una cosa se observa entre los alumnos de aquel culto entro de enseñanza, y que creemos debiera imitarse por todas las sociedades de ese higiénico sport, y es que están prohibidas las cargas con lo cual el juego es más elegante y se evita todo peligro. Es realmente feliz que en la juventud española se desarrolle la afición a los ejercicios corporales (Foot-ball en El Escorial, 1903, 11).

Declaraciones como las del reverendo Sardá (1908), las del Duque de la Salle de Rochemaure (1909) o las del arzobispo Josep Torras (1910), ponían en alza la influencia moral de los deportes. Como ejemplo práctico encontramos al arzobispo Torras, que en 1913 pagó un campo de fútbol para los jóvenes de la Congregación Mariana de Vic. Josep Casanovas (2001) señala que la clave del desarrollo del deporte en Vic estuvo en los sectores eclesiásticos los cuales se ocuparon de dirigir el deporte local al servicio del aleccionamiento moral y religioso. Hasta 1923, la única entidad deportiva de Vic fue el Esbarjó Marià (L’esportivitat de Vic, 1926, 11-12).

Esta acción de Vic no fue un caso aislado. En los años veinte, el movimiento católico estaba perfectamente organizado para ofrecer discusiones y posicionarse con elementos doctrinales sobre cómo había que encauzar el desarrollo de la educación física y el deporte (I Congreso Nacional de Educación Católica, 1925).

La incorporación de la cultura física en los colegios de las órdenes religiosas dedicadas a la enseñanza masculina -escolapios, salesianos, jesuitas, maristas, etc. -, tuvo un carácter netamente clasista. Estas congregaciones encontraron en el deporte no solo una herramienta para disciplinar y adoctrinar -infundirles valores virtuosos para servir mejor a Dios y a la Patria (Fray-Luis, 1919) - sino que a la vez vieron en él un excelente medio para el desarrollo de la conciencia pequeño burguesa en cuya formación estaban involucradas. Antes de llegar a los años veinte, muchos de estos colegios ya disponían de campos de fútbol y se habían constituido en asociaciones deportivas escolares que participaban en los campeonatos infantiles que ya se organizaban en algunas capitales. Así, por ejemplo, en poblaciones como Lérida, Tárrega o Balaguer los campeonatos tenían como promotores a los mismos profesores de educación física, quienes solían estar vinculados a las entidades deportivas más carismáticas. En Tárrega, el fútbol surgió en el Colegio de los Escolapios, que hacía 1913 formó un primer equipo llamado “Calasancio”. El impulso fue debido a los padres Carles Perelló y Vicente Verdejo, quienes animaron durante varias generaciones a la constitución de los clubes de esta población (Torrebadella, 2011a, 2012b). El padre Luis López (1918) reafirmaba el valor educativo e higiénico del fútbol en las Escuelas Pías.

Con todo, en los años veinte el fútbol escolar llegó a su máximo esplendor. Es la época en que emergen las hinchadas locales y se desarrollan los mitos de la "furia española”, los “diablos rojos”, etc. Se despliega toda una simbología futbolístico-patriotera ligada a los códigos de la masculinidad (Uría, 2008) que permitía atrapar desde muy pronto la subjetividad infantil. Los cromos coleccionables de los Ases del fútbol, cuentos deportivos, juegos, insignias o banderines, etc. convocaban el interés de los escolares, creaban solidaridad en torno a los colores locales, configuraban intereses y expectativas comunes; en definitiva, construían identidades ligadas sentimentalmente a las gestas deportivas de sus jugadores y de sus equipos. Es precisamente en esta época, a principios de los años veinte, cuando se produce una copiosísima bibliografía centrada principalmente en los “ases del fútbol” (Torrebadella y Nomdedeu, 2014).

En pocos años, el fútbol se había extendido entre los (pre)adolescentes y puede decirse que prácticamente no existía ningún club de fútbol que no tuviera uno o varios equipos infantiles. La demanda de campos deportivos para el fútbol escolar era habitual (R. C. M., 1923). La organización y promoción de encuentros entre equipos infantiles fue una estrategia que utilizaron las entidades cívicas, culturales, políticas y 
deportivas, pero también firmas comerciales. Sirva de ejemplo la organización de un partido entre dos equipos infantiles de dos poblaciones del Pirineo catalán con:

[...] el objetivo de estimular a los jugadores de ambas poblaciones hermanas a proseguir ardientemente a entrenándose, consecución de los altos fines de educación física y moral que el fútbol representa y el tener el noble deseo de honrar con su esfuerzo el nombre del pueblo respectivo, va El PIRINEO a obsequiar al equipo triunfante con once medallas, conmemorativas al partido, y a organizarles el encuentro. Todo esto y más se merecen los simpáticos representantes del fútbol infantil de Bellver y Puigcerdá, continúen cultivando el deporte de la salud física y de la disciplina y sabrán poner en toda ocasión el nombre de su pueblo en honroso sitio (Fútbol, 1923, 4).

Finalmente, también las autoridades políticas darían el visto bueno a la moda inglesa. Particularmente, el fútbol se consagró dentro del sistema educativo a partir de la instauración Cartilla Gimnástica Infantil (Ministerio de la Guerra, 1924) durante la Dictadura del general Miguel Primo de Rivera (1924-1931), la cual prescribía y reglamentaba las actividades de la educación física. En el programa de enseñanza la mencionada cartilla incluía el balompié, entre otros deportes, aunque sugería modificaciones del juego real respecto de las dimensiones del campo, la duración y otras condiciones que permitían adecuar la práctica a los requerimientos de la escuela primaria.

Con todo, el fútbol fue ganando adeptos entre la población infantil que en pocos años conseguiría una masa incondicional de aficionados. Este ambiente lo reflejaba muy bien José Lorenzo $(1924,5)$ cuando señalaba que ningún niño: "quiere ser otra cosa que as futbolista, y hasta en las aldeas más remotas e ignoradas los equipos se forman y las figuras preeminentes de este deporte son familiares”.

En los años veinte el fútbol cruzó la línea de la profesionalización del deporte descubriéndose como un emergente negocio (Pujadas \& Santacana, 2001) que, no obstante, no dejaba de suscitar controversias cuando de la escuela y de la infancia se trataba.

Así, hacia mediados la década, cuando el fútbol llegaba a su máxima plenitud, se desató una campaña refractaria hacia toda clase de deporte infantil siendo el detonante principal el fútbol. Tissié (1920) ya había alertado del carácter violento del fútbol para los niños y advirtía de la necesidad de una buena preparación física para practicarlo, mejor por adultos y jóvenes que por niños; una advertencia a consecuencia de la cual la Liga Girondina de Educación Física adoptó para los adolescentes escolares franceses el juego de barette como forma atenuada del fútbol.

El fútbol también fue acusado por Hebert (1925) de obrar en contra de los principios de la educación física. La obra de George Hebert, El sport contra educación física sacudió la conciencia tanto de profesores como de médicos y publicistas del deporte que acabaron por desaconsejar su práctica tanto por su carácter violento como por los desequilibrios higiénicos y sanitarios a los que su práctica conducía en la niñez. Por ejemplo, Andión señalaba que:

El foot-ball no ha sido nunca un ejercicio recomendable para practicarse por equipos infantiles, por muy diversas razones, unas de índole fisiológica -la ausencia de cultura física preparatoria, la rudeza de este deporte, los grandes esfuerzos que han de realizar organismos débiles y en formación, y muchas otras- y otras de índole moral, tan atendibles o más que las precedentes, y que obedecen a que, dada la inconsciencia de los jugadores de los equipos infantiles -todos menores de quince años-, se entregan a la lucha con un ardor perjudicial, y la picardía de algunos, contrastando con la inocencia de los más, hace que este deporte no sea educativo, pues los golpea intencionados y las cargas alevosas abundantes influyen poderosamente en la moral de los actuantes (Andión, 1925, 5).

Entre los detractores del fútbol infantil se encontraban, aparte del ya citado Marcelo Sanz, personalidades tan 
influyentes en el escenario deportivo del momento como Ricardo Ruiz Ferry, el doctor César Juarros, Adolfo Revuelta, Román Sánchez, Fernández Trapiella o, el capitán José Hermosa, el cual antepuso al fútbol otros juegos deportivos de equipo (Torrebadella, 2012a, 2013). Estos críticos portavoces advertían de los peligros del fútbol infantil e insistían en la concienciación de hacer llegar políticas saludables a la educación física escolar. No obstante, había quienes sostenían que "sí puede admitirse la práctica del fútbol entre equipos infantiles, de fuerzas equivalentes, limitando el tiempo de duración de los partidos en consonancia con su estado de desarrollo físico" (Cabeza, 1926, 149).

De todas maneras, con detractores y partidarios enfrentados, en los años treinta el fútbol había ganado por completo la partida a la educación física gimnástica. Como señalaba José Arias Cardona, en esa época el fútbol ya alcanzaba a todas las clases sociales y hasta en los lugares más recónditos podía encontrarse un campo de juego. Se trataba del éxito de un juego que, en palabras de José Arias $(1934,1)$ "siempre es violento y en ocasiones brutal”, pero a la vez "[...] es un ejercicio de fuerza, de valor y más que todo de disciplina”.

En abril de 1936, la Federación Deportiva de Bachillerato ponía los cimientos para institucionalizar el deporte escolar con la organización del primer campeonato de fútbol escolar de Madrid en el que participan un total de once institutos: Pérez Galdós, Quevedo, Velázquez, Cardenal Cisneros, Lópe de Vega, el Instituto Escuela -equipos A y B-, Nebrija, Calderón, Cervantes, Lagasca y San Isidro (El Campeonato escolar, 1936, 16).

\section{El fútbol escolar como dispositivo disciplinario}

De acuerdo con la tradición crítica -coincidente en esto con el análisis foucaultiano- la institución escolar se incrusta en el cuerpo infantil configurando una regularidad y un orden, tanto físico como ideológico, que operan al servicio de la propia institución. Si bien es cierto que dicha regularidad y orden se inculcan casi siempre a través de la imposición, la coerción o el castigo, es la persuasiva insistencia de la rutina, el ejercicio y el hábito lo permite establecer el indeleble vínculo con la modalidad de saber y de práctica escolar. En todo caso, el dispositivo disciplinar(io) en que consiste el espacio-tiempo escolar es una resultante de la combinatoria de los mecanismos físicos y microfísicos de sujeción en cuyo interior se produce un nuevo sujeto: el sujeto escolarmente educado. Pues bien, el fútbol escolar se mostró en los inicios del siglo XX como un agente facilitador de dicho dispositivo en la medida en que fue capaz de conjugar muchos de los procedimientos y estrategias disciplinarias propias de la escuela con aquello de lo que la escuela carecía: el vínculo que supone la adhesión emotiva entre el poder y su sujeto y que el fútbol podía proporcionar a través del placer inmediato del juego.

En un contexto en el que la educación física había quedado constreñida a los ideales de la rectitud -el modelo triunfante de la gimnasia filantrópica-, el fútbol se mostraba como un espacio-tiempo de expansión del cuerpo que los escolares ansiaban; pero, no obstante, un espacio-tiempo de disciplina y ejercitación que el ojo del poder no dejaba de escrutar. Al fin y al cabo, el equipo de fútbol es, como decía Tunmer y Fraysse (ca., 1910) un batallón infantil que dirige un capitán. O, como apuntaba Josep Elias (1914, 36), “una batalla en toda regla” para vencer al enemigo dirigida por un capitán al que se le obedece ciegamente y que "es el dueño absoluto de sus hombres, debiendo imponer la más rigurosa disciplina”. En parecido sentido, el influyente profesor Tissié, advertía que:

Desde el punto de vista de la estrategia de combate y de la formación del hombre para el servicio militar, el foot-ball permite revelarse los caracteres y afirmarse los temperamentos de jefe. El football es la escuela de la obediencia dentro de la libre iniciativa (Tissié, 1920, 158). 
Fue a partir de la Guerra de Marruecos cuando se organizaron masivamente los stocks corporales de la infancia. Hacia 1912 rebrotaron los batallones infantiles apadrinados por las instituciones católicas como las Escuelas Pías. Es la época en que surgen los Exploradores de España (Boy Scouts) -un eufemismo a la inglesa de estos mismos batallones infantiles (Torrebadella, 2015) - cuyo proyecto de contención a la vez que de militarización de la infancia iría a la par que el desarrollo del deporte en este tipo de escuelas. A esto habían quedado "reducidos los frutos de la educación física primaria”, que diría Hernández (1915, 9), un maestro de escuela desencantado.

En esto, la ILE, que en el pasado se había opuesto a esa clase de organizaciones, no se pronunció y lo asumió tácitamente. Y es que la figura del "hombre nuevo" -un mito restituido a partir del gentleman-, que tanto había idealizado el regeneracionismo (González-Aja, 2011), no fue más que la retórica que las elites intelectuales liberales emplearon para cautivar a la juventud al servicio de la clase dirigente. Claro que, en general, el regeneracionismo nunca se había interesado por los problemas de la clase obrera, sino más bien, se había orientado a instruirla para dominarla. A este respecto, el discurso subyacente del regeneracionismo fue encarnado por la imagen pública de Alfonso XIII, precisamente cuando los jóvenes obreros sin recursos eran obligados a ir al deporte de la guerra; una imagen frívola y clasista del monarca -Rey, soldado, deportista (González-Aja, 2011) - que sirvió para legitimar el deporte entre las élites aunque también, a la postre, y como consecuencia de la indignación popular que suscitaba, serviría para apuntalar en el extremo opuesto un deporte obrero y popular, un deporte enfrentado a la monarquía y a la política de señoritos y caciques.

En cualquier caso, deporte de clase y deporte popular compartían en este contexto, el propósito subyacente del disciplinamiento. Tanto para las clases que podían practicar el deporte de la caza, el tenis o el polo como para los que habían de contentase con el fútbol, la condición deportiva imponía inequívocamente la enseña de la obediencia a la autoridad, la cultura del esfuerzo y cierta pátina de distinción física y moral; pero, sobre todo, se intuía que el deporte poseía la capacidad de disuadir a la juventud de cualquier veleidad crítica o contestataria. En gran medida, en eso consistía la naturaleza regeneracionista del deporte: no tanto en la revitalización racial como en un adoctrinamiento muscular y emotivo que silenciosamente se adueñaba de la juventud.

Cuando en los colegios de los niños ricos se jugaba al fútbol, la mayoría de "los otros niños”, seguía sin escolarizar, muchos de ellos trabajando en la industria fabril o artesanal y bastantes se mantenían ociosos y algunos vagabundos. Para estos, el deporte escolar también fue promovido como un medio de protección. Al igual que en muchos casos lo fue la escuela, los campos de juego fueron concebidos como un espacio de reclutamiento y vigilancia de los niños rebeldes tanto más eficaz cuanto que el fútbol aparecía como un premio al esfuerzo; una ilusoria compensación que el niño recibía por su sometimiento a los ideales del buen gobierno ciudadano que, no obstante, no pasó desapercibida a los sectores más críticos de la sociedad. Particularmente, las escuelas obreras de vinculación anarquista reprobaron tanto la práctica gimnástica disciplinar como el deporte; vieron el fútbol como una preparación pre-militar, una plaga que ponía en inferioridad a los mismos hombres (Estruch, 1928), que situaba "frente a frente, no ya a los individuos -ellos son meros peleles, máquinas inconscientes-, sino a los pueblos mismos”, para satisfacción de un inconfesable salvajismo” (Olavarrieta, 1930, 49).

Pero en un momento de conflictividad internacional como el que se estaba viviendo, donde la efervescencia nacionalista constituía un punto de apoyo ideológico, los Estados no estaban dispuestos a renunciar al potencial propagandístico del deporte a través de los sentimientos de pertenencia, simples pero intensos, casi tribales que siempre este ha despertado (Vicente, 2011). Así, tras la I Guerra Mundial el fútbol fue objeto de promoción en prácticamente todos los países occidentales (Torrebadella, 2016); los defensores de la "pedagogía deportiva” o de la "ética de los valores olímpicos”, que alimentara el barón de Coubertin 
insistieron en proclamar las excelencias del deporte, sobre todo, su potencialidad para la transformación moral del hombre (Brown, 2012; Chatziefstathiou \& Henry, 2009).

En particular, el fútbol, fue presentado como como un juego trascendente en el que solamente sobreviven los más fuertes; y se hizo con tal fuerza persuasiva que en poco tiempo se convirtió en un eficaz elemento unificador e identificador de cada nación, de cada patria, que espoleaba la hostilidad latente entre estados y razas. En el período del Directorio de Primo Rivera, la estrecha alianza entre la iglesia y el ejército constituyó una poderosa estructura institucional a través de la que se fraguó el adoctrinamiento patriótico y católico con el concurso del fútbol. Obras como la de Vuillermet (1925), son enteramente anuentes con los más rancios discursos patrióticos, adornados ahora con el deportismo, para introducirse sutilmente en las asociaciones escolares. El fútbol, como deporte de masas, se vislumbraba como el parapeto perfecto donde ocultar el subyacente dispositivo disciplinario de saber/poder para la construcción de una nueva ciudadanía, una ciudadanía mansa y sin pretensiones. Tales parecieron ser las intenciones, por ejemplo, del Servicio Nacional de Educación Física, Ciudadanía y Premilitar a través de uno concienzudo programa que confeccionó el Directorio Militar para controlar y dirigir todo el asociacionismo deportivo popular (Comité Nacional de Cultura Física, 1929). A partir de dicho programa los clubes deportivos actuaron como un tercer sector que colaboró estrechamente en la educación nacional; una educación en la que el ejército extendió su poder fuera de los cuarteles para imponer una nueva educación social: la nacionalización y militarización de las masas mediante un adoctrinamiento para el que el deporte, inculcado desde la edad escolar, constituía el mejor aglutinante ideológico (Quiroga, 2004).

Es así que con el general Primo de Rivera los deportistas empezaron a encumbrarse como modelos sociales para los jóvenes de las familias proletarias. El régimen del Directorio institucionalizó mecanismos de gobernabilidad que ejercieron su poder en las asociaciones deportivas populares y patrióticas, encarnadas por los clubes de fútbol, con el fin de enrolar en sus filas una incondicional militancia juvenil. Si las asociaciones futbolísticas infantiles sirvieron al principio para instruir en una educación clasista a los hijos de las clases acomodadas, lejos de la corrupción física y de los vicios morales de la clase obrera, la popularización del juego sirvió para desinfectar a dicha clase; fue un eficaz dispositivo para enderezar y domesticar los impulsos de la juventud a gran escala. El fútbol aparecía ya, inequívocamente como el mecanismo socializador por excelencia; como una eficaz agencia de control de la población masculina (Barbero, 2006).

\section{Conclusiones}

Como plantea Kirk (1990), históricamente la adscripción de la educación física en el currículo escolar poco ha tenido que ver con la educación. En España fue ILE la que, asumiendo parte del modelo educativo de las Public Schools y haciéndose cómplice del discurso regeneracionista finisecular, proclamó el ideario de la educación integral a través de los juegos corporales que daban cobertura pedagógica e higiénica a la práctica balompédica.

Aparte del vigor y resistencia física que procuraba dicha práctica -lo que muchos vieron un buen recurso de ejercitación premilitar-, el poder de convocatoria que demostró desde muy pronto fue utilizado como medio de socialización, como mecanismo de promoción de los valores burgueses en alza y, particularmente, aquellos que como el conformismo, el auto-sacrificio, la gratificación respetuosa, el carácter y la masculinidad, etc. podían ponerse "al servicio del nacionalismo y el control social a través del fenómeno de la obediencia a la autoridad, del servilismo, y de una aceptación del orden de la sociedad” (Kirk, 1990, 58).

En el contexto de principios de siglo, el clima de enfrentamiento bélico -sobre todo alrededor de la I Guerra Mundial-actuó como amalgama ideológica nacionalista que uniría de manera indisoluble fútbol y excitación patriótica, tan útil para movilizar y desmovilizar a las masas desde el poder. El entorno infantil y escolar no 
estuvo al margen de condición, que actuaría como eficaz herramienta para popularizar e incentivar su mercantilización. Con el fútbol se ponía en marcha un nuevo dispositivo de colonización de la infancia; un mecanismo bio-político que, desde el sentimiento de identidad escolar que proporcionaba la rivalidad entre escuelas, barrios o ciudades, suscitaba y estimulaba una nueva forma de adscripción emotiva e ideológica.

La configuración del fútbol como dispositivo disciplinario y de dominación se instaló en el interior de las organizaciones escolares donde aplicaría sus silenciosas técnicas de saber/poder. No era más que una política social, un dispositivo más de control a través del autogobierno que, de acuerdo con Ibáñez (1982), operaba en la masa mediante controles individuales, inscribía la vigilancia en el espacio del sujeto, sustituía la ley por la norma y colocaba la necesidad en el lugar de la prescripción.

La escuela y el club deportivo sufragaron la inoculación de los códigos disciplinarios del deporte cuyos valores socializadores y aceptación del con el statu quo (esfuerzo, trabajo, sacrificio, lucha, respeto, superación,...) se habían erigido de forma natural en el ámbito educativo. El club deportivo se presentó como una extensión de la parroquia la cual encontró en el fútbol el mejor proyecto para apuntalar la comunión de cuerpos y almas, el salvífico imaginario de la sanidad y la santidad unidos por el balón.

No en vano el fútbol fue protegido y auspiciado por todo tipo de estados, estados totalitarios y fascistas, y no mucho menos los estados democráticos, hicieron acopio de su poder de convocatoria. En España, sería con el franquismo cuando este deporte alcanzó su mayor protección por parte del Estado (González-Aja, 2005). Las organizaciones deportivas, preferentemente los clubes de fútbol de raíz obrera y los elitistas colegios privados estuvieron tutelados por la organización deportiva nacional. En las escuelas públicas, el fútbol quedaba reducido a las escenas del recreo escolar, permeando el deseo de pertenecer al humilde club de barrio. El país, encerrado autárticamente en sí mismo, con el fútbol mantuvo bajo control a toda una generación de jóvenes que aspiraban a convertirse en "ases del balón” y a representar algún día a la selección nacional. De alguna manera, con el fútbol, el régimen aspiraba a restablecer simbólicamente la otrora hegemonía española en el concierto internacional; pero como sostenía Josep Elias $(1914,25)$ el "punto de partida del verdadero fútbol es, sin duda alguna, el del origen de la supremacía actual de los británicos”.

Hoy el fútbol trata de erigirse mediáticamente como el principal embajador de los llamados valores del deporte y crea su propio espacio mitológico (Barthes, 1999). Sin embargo, sus implicaciones sociales, culturales e ideológicas van más allá de una práctica social inocua, neutra; alarga sus tentáculos y como dice Kirk (1990) atrapa en sus redes a la educación física escolar; el fútbol estructura códigos de conducta, imaginarios, representaciones, usos, gestos, lenguajes, etc. que construyen subjetividades individual y colectivas y que operan, en última instancia, como dispositivos de sujeción (Vicente, 2012).

Con el deporte, y especialmente con los modelos de la iniciación precoz en auge, se puede decir que la infancia permanece atrapada "en una red de reglas, códigos y reglamentos en el interior de una progresiva obsesión por el entrenamiento físico" (Varela, 1991, 246), que hoy mercantiliza los cuerpos. Pero esta primigenia naturaleza del fútbol, que según Parlebas (1988) hunde sus raíces en la sociología de la guerra, sublima el enfrentamiento entre naciones no solo en lo comercial, sino que también en lo ideológico. En palabras de Screti (2011), el fútbol no deja de ser una metafórica expresión de la guerra que continúa realizándose con otros medios; medios entre los que, sin duda, figura la manipulación de las emociones infantiles.

\section{Notas}

1 Desde luego, no caben dudas sobre las reminiscencias medievales en la inspiración del fútbol contemporáneo, pero sería ingenuo pensar en este como una mera evolución reglamentación o transformación técnica de viejas prácticas populares. 
$\underline{2}$ La edad para participar estaba entre los ocho y quince años, además de tener más de 1,10 metros y menos de 1,50 metros de estatura. Los jugadores no podían haber disputado más de cuatro equipos en la presente temporada como equipo federado. Cada equipo debía poseer su propio campo de fútbol.

\section{Referencias}

Alcántara, P. (1924). Mis memorias y consejos prácticos para el entrenamiento. Barcelona: Imp. Garrofé.

Almeida, A. S. (2003). Les "Public Shools" i la reforma educativa de Thomas Arnold (1828-1842). Temps d'Educació, 27, 305-329.

Álvarez-Santullano, L. (1903). Desde Oviedo. La vida universitaria. La Escuela Moderna, 147, 447-451.

Andión, N. (1925, octubre 3). Los peligros del foot-ball infantil. El Imparcial, p. 5.

Arias, J. (1934). Guía futbolística autorizada por los respectivos clubs. Barcelona: Tip. Juan Gustems.

Bahamonde, A. (2002). El Real Madrid en la historia de España. Madrid: Taurus.

Bahamonde, A. (2011). La escalada del deporte en España en los orígenes de la sociedad de masas, 19001936. En X. Pujadas (coord.). Atletas y ciudadanos. Historia social del deporte en España, 1870-2010 (pp. 89-123). Madrid: Alianza Editorial.

Barba, A. (1912). Football, basse ball y lawn tennis. Barcelona: Ed. Sucesores de M. Soler.

Barbero, J. I. (1990). La aparición de los deportes en las "Publics Schools”, ¿'Thomas Arnold o los cristianos musculares. Perspectivas de la actividad física y el deporte, 5, 34-36.

Barbero, J. I. (2006). Deporte y cultura: de la modernidad a los discursos posmodernos del cuerpo. Educación Física y Deporte, 25(1), 69-93.

Barthes, R. (1999). Mitologías. Madrid: Siglo veintiuno de España editores.

Benítez, A. (1896, enero 15). Football. Crónica del Sport, p. 7.

Brasó, J., \& Torrebadella, X. (2014). El joc del 'rescat' a Catalunya. Un projecte educatiu a l'Escola del Mar de Pere Vergés. Temps d’Educació, 47, 191-212.

Brohm, J. M. (1993). Tesis sobre el deporte. En Materiales de sociología del deporte (pp. 47-55). La Piqueta: Madrid.

Brown, S. (2012). De Coubertin's Olympism and the Laugh of Michel Foucault: Crisis Discourse and the Olympic Games. Quest, 64(3), 150-163. DOI: https://doi.org/10.1080/00336297.2012.693750

Cabeza, M. (1926). Las leyes del juego del Fútbol asociación. Barcelona: Ed. Imp. de Eugenio Subirana.

Calvo, F. (2012). Escuela, espacio y poder. Estudios sobre la educación y territorio. Barcelona: UOC.

Casanovas, J. (2001). L’esport a Vic. De símbol social elitista a pràctica formativa. Avenç, 257, 48-51.

Castro, M. (2012). Orígenes del fútbol Sevillano. Madrid: Editorial Punto Rojo.

Chatziefstathiou, D., \& Henry, I. (2009). Technologies of power, governmentality and Olympic discourses: A Foucauldian analysis for understanding the discursive constructions of the Olympic ideology. Esporte $e$ Sociedade, 12, 1-28. Tomado el 28 de octubre de 2014 de http://www.uff.br/esportesociedade/pdf/es1206.pdf

Ciria, P. (2013). El sueño de ser grandes. Historia del nacimiento del fútbol en Zaragoza. Zaragoza: Mira ediciones. 
Climent, F. (1901, enero 20). Campos de juego. Los Deportes, pp. 38-39.

Climent, F. (1904). Educación de los niños. Barcelona: Sucesores de Manuel Soler.

Comité Nacional de Cultura Física: Escuela Central de Gimnasia. Curso de información para comandantes del Ejército sobre educación física, ciudadana y premilitar. Toledo: Imp. del Colegio de María Cristina.

Concurso Copa Escolar (1913, noviembre 13). El Mundo Deportivo, p. 5.

Concurso Copa Escolar (1913, diciembre 14). El Mundo Deportivo, p. 4.

Corredissas (1902, setiembre 19). Gaceta de Sports. El Joch del futbol. La Veu de Catalunya, p. 2.

Corriente, F., \& Montero, J. (2011). Citius, Altius, Fortius: El libro negro del deporte. Logroño: Pepitas de Calabaza.

Cuesta, P. (1994). La escuela en la restauración de la sociedad española (1900-1923). Madrid: Siglo Veintiuno Editores.

De la Salle de Rochemaure (1909). Gran Festa Sportiva. Aurillac: Imp. Moderrne.

Del Cura, M., \& Huertas, R. (2009). Higiene mental y educación terapéutica: La pedagogía ortofrénica en la España del primer tercio del siglo XX. Historia de la Educación, 28, 80-107.

Delgado, B. (1997). La generación del 98 y la educación española. Revista de Educación, Ext., 11-31.

Demolins, E. (1899). En qué consiste la superioridad de los anglo-sajones. Madrid: Librería de Victoriano Suárez.

Deportes infantiles (1914, febrero 11). Mundo Gráfico, p. 5.

Domínguez, A. (2011). La práctica de la modernidad: orígenes y consolidación de la cultura deportiva en España, 1870-1914. En X. Pujadas, (coord.). Atletas y ciudadanos. Historia social del deporte en España, 1870-2010 (pp. 55-88). Madrid: Alianza Editorial.

Durkheim, E. (1986). Educación y sociología. Barcelona: Península.

El Campeonato escolar (1936, abril 2). El Siglo Futuro, p. 16.

Elias, J. (1901, marzo 1). Sport. Lo foot-ball en la present temporada a Barcelona- La Ilustració Llevantina, p. 1.

Elias, J. (1903, septiembre 20). Sports. La Ilustració Catalana, p. 259.

Elias, J. (1914). Football asociación. Barcelona: R. Tobeña.

Elias, N. (1988) El proceso de la civilización. Madrid: F.C.E.

Elias, N., \& Dunning, E. (1992). Deporte y ocio en el proceso de civilización. Madrid: FCE.

Estruch, J. (1928, abril 1). Futbolismo y boxeo. Acción Cultural, p. 1.

Federación Catalana de Clubs de Foot-ball (1910, abril 7). Campeonato Infantil. El Mundo Deportivo, p. 4.

Femenía, Á. (1923). Reglamento Internacional de Foot-ball Asociación. Barcelona: Unión Librera de Editores.

Fernández Enguita, M. (1990). La cara oculta de la escuela: Madrid: Siglo Veintiuno de España Editores. 
Fernández-Soria, J. M. (2014). The presence of the British education model in Spain: reception through the Institución Libre de Enseñanza. History of Education: Journal of the History of Education Society, 43(1), 5071, DOI: https://doi.org/10.1080/0046760X.2013.844277

Ferrer, D. (1901, enero 27). Cartilla de Gimnasia higiénica. Los Deportes, pp. 52-53.

Festival deportivo en Sabadell (1913, julio 24). El Mundo Deportivo, pp. 4-5.

Foot-ball en El Escorial (1903, abril 1). Nuevo Mundo, p. 11.

Foucault, M. (1991). La gubernamentalidad. En Espacios de poder. Madrid: La Piqueta.

Fray-Luis (1919, julio 15). La edad crítica. La Educación Física, p. 20.

Fútbol (1923, julio 8). El Pirineo, p. 4.

Galí, A. (1983). Historia de les institucions i del moviment cultural a Catalunya, 1900 a 1936, vol. X. Barcelona: Fundació Alexandre Galí.

García-Candau, J. (1996). Épica y lírica del fútbol. Madrid: Alianza Editorial.

García, J. (1902). Las sociedades escolares humanitarias. Los juegos y paseos higiénicos y su influencia sobre la educación moral y física de la niñez, Málaga: Imp. y Lit. de R. Párraga.

García, J. (1903, marzo 31). Parques deportivos. Andalucía Científica, pp. 104-105.

García, P. de A. (1898). Llamamiento. La Escuela Moderna, 88, 1-7.

Giner, F. (1884). Campos escolares. Madrid: Est. Tip. de “El Correo”.

Giner, F. (1887). El ayuntamiento de Madrid y el juego de los niños. BILE, 259, 338-339.

González-Aja, T. (2005). Monje y soldado. La imagen masculina durante el franquismo. RICYDE. Revista Internacional de Ciencias del Deporte, 1(1), 64-83. Doi: https://doi.org/10.5232/ricyde

González-Aja, T. (2011). Sport, Nationalism and Militarism - Alfonso XIII: Sportsman, Soldier, King, The International Journal of the History of Sport, 28(14), 1987-2030, DOI: https://doi.org/10.1080/09523367.2011.604825

H. S. (1922, octubre 27). Lérida Campeonatos infantiles de fútbol y atletismo. La Jornada Deportiva, p. 16.

Harvey, A. (2013). The Emergence of Football in Nineteenth-Century England: The Historiographic Debate. International Journal of the History of Sport, 30(18), 2154-2163, DOI: https://doi.org/10.1080/09523367.2013.839551

Hebert, G. (1925). El sport contra la Educación física. Barcelona: Imp. Mercantil.

Hernández, B. (1915, marzo 30). La pedagogía y la guerra. Acción Socialista, pp. 8-10.

I Congreso Nacional de Educación Católica (1925). Madrid: Tip. de la "Revista de Archivos".

Ibáñez, T. (1982). Poder y libertad. Estudio sobre la naturaleza, las modalidades y los mecanismos de las relaciones de poder. Barcelona: Hora.

Intimidades (1903, marzo 1). Los Deportes, p. 134.

Kirk, D. (1990). Educación Física y currículum. Valencia: Universidad de Valencia.

L'esportivitat de Vic (1926, julio 6). L’Esport Català, pp. 11-12. 
Lerena, C. (1991). Escuela, ideología y clases sociales en España. Crítica de la sociología empirista de la educación ( $4^{\mathrm{a}}$ ed.). Barcelona: Ariel.

López Serra, F. (1998). Historia de la educación física de 1876 a 1898. La Institución Libre de Enseñanza. Madrid: Ed. Gymnos.

López, L. (1918, enero 3). El deporte futbolístico en las Escuelas Pías. Madrid-Sport, pp. 41-42.

Lorenzo, J. (1924, julio 8). La afición a los deporte en España no puede acabar. Aire Libre, p. 5.

Mandell, R. (1986). Historia cultural del deporte. Barcelona: Bellaterra.

McFarland, A. (2008). Regeneracionismo del cuerpo: the arguments for implanting athletics in Spain. Sport in Society, 11(6), 615-629. DOI: https://doi.org/10.1080/17430430802283823

McFarland, A. (2011). The Importance of Reception: Explaining Sport's Success in Early Twentieth-century Spain. European Review, 19, 527-543. DOI: https://doi.org/10.1017/S1062798711000172

Medel, F. (1903, febrero 18). Un Festejo más. Proposición aceptable. El Diario de Murcia, p. 1.

Ministerio de la Guerra (1924). Cartilla Gimnástica Infantil. Madrid: Sucesores de Rivadeneyra.

Moraes, M. (2012). Escola e educação física: maquinaria disciplinar, biopolítica e generificante. Revista Brasileira de Ciências do Esporte, 34(2), 343-357. DOI: https://doi.org/10.1590/S0101-32892012000200007

Museo Pedagógico Nacional (1895, mayo 15). Proyecto de reforma del Museo Pedagógico Nacional. La Gaceta de Instrucción Pública, pp. 117-119.

Nomdedeu, A. (2009). Diccionario del fútbol. A Coruña: Universidad da Coruña.

Ocaña, M. (1906, octubre 18). Vigo. El Mundo Deportivo, p. 4.

Olavarrieta, J. B. (1930). La salud por el ejercicio. Ávila: Tip. y Enc. de Senén Martín.

Opisso, A. (1915, octubre 22). Los deportes como agentes curativos. La Vanguardia, p. 8.

Ortega, J. M. (1996). Románticos sportmans. Historia del deporte vallisoletano en el siglo XIX. Valladolid: Ayuntamiento de Valladolid-Fundación Municipal de Deportes.

Oses, J. (1915). Juegos de campo para niños. Los grandes y pequeños deportes al aire libre. Barcelona: Perelló i Vergés.

Parlebas, P. (1988). Elementos de Sociología del Deporte. Málaga: Junta de Andalucía.

Pastor-Ruíz, F. (2002). Historia del deporte escolar en el territorio histórico de Bizkaia. Pamplona: Universidad de Navarra. [tesis doctoral]

Pedregal, F. (1895). La educación gimnástica. Madrid: Imp. de los Hijos de M. G. Hernández.

Pujadas, X., \& Santacana, C. (2001). La mercantilización del ocio deportivo en España. El caso del fútbol (1900-1928). Historia social, 47, 147-168.

Quintanas, A. (2011). Higienismo y medicina social: poderes de normalización y formas de sujeción de las clases populares. Isegoría, 44, 273-284.

Quiroga, A. (2004) 'Los apóstoles de la Patria'. El Ejército como instrumento de nacionalización de masas durante al Dictadura de Primo de Rivera. Mélanges de la Casa de Velázquez, 34(1), 243-272.

R. C. M. (1923, enero 18). Faltan campos de deportes para nuestros infantiles. La pelota semanal, p. 1. 
Rebollo, A. (2009). Notas para la historia del Gran Gimnasio de Badajoz (1868-1936). Revista de Estudios Extremeños, 2, 865-932.

Rodríguez, Á. (2008). El deporte en la construcción del espacio social. Madrid: Centro de Investigaciones Sociológicas.

Rodríguez, G. P. (1919, febrero 27). Modernas orientaciones de los deportes II. El Mundo Deportivo, p. 1.

Salvador, J. L. (2004). El deporte en occidente. Historia, cultura y política. Madrid: Cátedra.

Santa Susana, M. de (1896, enero 15). Football. Crónica del Sport, p. 7.

Sanz, M. (1913). Ensayo de una higiene deportiva o de los deportes ante la higiene. Madrid: Imp. Correspondencia Militar.

Sardá, F. (1908). L’sport católich. Barcelona: Lib. Tip. Católica.

Screti, F. (2011). Fútbol, guerra, naciones y política. Razón y Palabra, 74. Recuperado el 29 de octubre de 2014 de http://www.razonypalabra.org.mx/N/N74/VARIA74/34ScretiV74.pdf

Sena, M. (1906, agosto 9). San Sebastián. Football. Campeonato de fútbol infantil. El Mundo Deportivo, p. 6.

Serra, A. (1907, febrero 9). El foot-ball al alcance de todos, para uso de Colegios, Universidades, etc. Los Deportes, pp. 151-152.

Smith, J. (2002). Michel Foucault: Sport, power, technologies and governmentality. In J. Magire \& K. Young (eds.). Theory, sport \& society (pp. 293-314). Oxford: Elsevier Science.

Solana, E. (ca. 1909). Curso completo de pedagogía. Madrid: El Magisterio Español.

Spencer, H. (1879). De la educación intelectual, moral y física. Sevilla: Imp. de R. Baldaraque.

Tissié, Ph. (1920). Juegos y deportes en terapéutica. En A. Gilber y P. Carnot (dir.) Fisioterapia IV (Mecanoterapia, reeducación, deportes, método de Bier, hidroterapia) t. VII (pp. 116-184). Barcelona: Salvat y $\mathrm{C}^{\mathrm{a}}$.

Torras, J. (1910). L’Atletisme cristià. Vic: Imp. Anglada.

Torrebadella-Flix, X., \& Nomdedeu-Rull, A. (2015). Los primeros libros de fútbol publicados en España (1900-1919). Revista General de Información y Documentación, 25(1) [en prensa]

Torrebadella, X. (1999). L’educació física en el Liceo Escolar de Lleida (1906-1939): Un model de renovació pedagógica. En Aplicacions de les activitats fisico-esportives: Actes IV Congrés de l'Activitat Física, l'Esport i la Recreació (pp. 75-85). Lleida: INEFC-UdL.

Torrebadella, X. (2011a). El boom de l'esport. Ideologia i Societat a l'esport targarí (1920-1937). Urtx, 25, 423-455.

Torrebadella, X. (2011b). Repertorio bibliográfico inédito de la educación física y el deporte en España (1800-1939). Madrid: Fundación Universitaria Española.

Torrebadella, X. (2012a). El deporte contra la educación física. Un siglo de discusión pedagógica y doctrinal en la educación contemporánea. Movimiento humano, 4, 73-98.

Torrebadella, X. (2012b). El fútbol en Lleida. De los orígenes a la consolidación del futbol comarcal (19101936). Cuadernos de Fútbol (CIHEFE), junio, setiembre y octubre, 33, 35 y 36. Recuperado en 10 de octubre de 2015 desde http://www.cihefe.es/cuadernosdefutbol/author/xavier-torrebadella/ 
Torrebadella, X. (2012c). Los orígenes de una ciudad olímpica: Barcelona y el asociacionismo deportivo decimonónico ante la gestación de los primeros Juegos Olímpicos. Citius, Altius, Fortius, 5(2), 91-134.

Torrebadella, X. (2012d). Orígenes del Fútbol en Barcelona (1892-1903). RICYDE. Revista Internacional de Ciencias del Deporte, 27, 80-102.

Torrebadella, X. (2013). Anotaciones al balonmano en el contexto histórico del deporte en España (19001939). e-balonmano. Revista de Ciencias del Deporte, 9(2), 115-134.

Torrebadella, X. (2014a). El push-ball en España. La historia de un deporte que no alcanzó "carta de naturaleza” (1897-1936). Agon. Intertational Journal Sport o Sciences, 4(2), 71-84.

Torrebadella, X. (2014b). Los apóstoles de la educación física. Trece semblanzas profesionales en la educación física española contemporánea. Revista Española de Educación Física, 406, 57-76.

Torrebadella, X. (2014c). Regeneracionismo e impacto de la crisis de 1898 en la educación física y el deporte español. Arbor, 190(769): a173. doi: http://dx.doi.org/10.3989/arbor.2014.769n5012

Torrebadella, X. (2015). Los batallones infantiles en la educación física española (1890-1931). ODEP. Revista Observatorio del deporte, 1(1), 32-70.

Torrebadella, X. (2016). España, regeneracionismo y deporte durante la I Guerra Mundial. Athenea Digital. Revista de Pensamiento e Investigación Social, 16(1), 237-261. doi: http://dx.doi.org/10.5565/rev/athenea.1501

Torrebadella, X., \& Brasó, J. (2015). El ‘marro’ un juego tradicional y popular en la educación física española (1807-1936). Revista Complutense de Educación, [en prensa]

Torrebadella, X., \& Nomdedeu, A. (2013). Foot-ball, futbol, balompié... Los inicios de la adaptación del vocabulario deportivo de origen anglosajón. RICYDE. Revista Internacional de Ciencias del Deporte, 31, 522.

Torrebadella, X., \& Nomdedeu, A. (2014). Bibliographic Repertoire of Football in Spain (1900-1936). 121 works to interpret the social impact of football in contemporary history. Apunts. Educación Física y Deporte, 115, 7-32. http://dx.doi.org/10.5672/apunts.2014-0983.cat.(2014/1).115.01

Tunmer, N. G., \& Fraysse, E. (ca. 1910). Foot-ball, según los consejos de M. M. Tunmer y Fraysse, Waterpolo. Barcelona: Editorial Ibero-americana.

Turuzeta, J. (2012). El Athletic Club. San Sebastian: Txertoa argitaletxea.

Uría, J. (2008). Imágenes de la masculinidad el fútbol, español en los años veinte. Ayer, 72(4), 121-155.

Valserra, F. (1944). Historia del deporte. Barcelona: Ed. Plus-Ultra.

Van Dijk, T. A. (2003). Ideología y discurso. Barcelona: Ariel.

Varela, J. (1983). La escuela obligatoria, espacio de civilización del niño obrero. 1900-1904. En la obra colectiva Perspectivas actuales en sociología de la educación. I Congreso Internacional de Sociología de la Educación (pp. 177-198). Madrid: ICE de la UAM.

Varela, J. (1991). El cuerpo de la infancia. Elementos para una genealogía de la ortopedia pedagógica. En Sociedad Cultura y Educación. Homenaje a la memoria de Carlos Lerena Alesón (pp. 229-248). Madrid: Universidad Complutense de Madrid.

Varela, J., \& Álvarez-Uría, F. (1991). Arqueología de la Escuela. Madrid: La Piqueta. 
Veblen, T. (2008). Teoría de la clase ociosa. Madrid: Alianza Editorial.

Viada, A. (1903). Manual de Sport. Madrid: Adrian Romo.

Vicente, M. (2005). El cuerpo de la educación física: Dialéctica de la diferencia. Revista Iberoamericana de Educación (Madrid), 39, 53-72.

Vicente, M. (2011). De la diversidad del concepto de deporte y su naturaleza. En E. Isidori y A. Fraile (coord.) La pedagogía del deporte hoy. Escenarios y desafíos (pp. 43-80). Roma: Edizioni Nuova Cultura.

Vicente, M. (2012). El discurso técnico de la educación física o el techo de cristal: Bosquejo de un debate sobre el código disciplinar de la educación física y su precaria legitimidad. Estudios pedagógicos (Valdivia), 38 (Especial), 89-109.

Vigarello, G. (2005). Corregir el cuerpo. Historia de un poder pedagógico. Buenos Aires: Nueva Visión.

Viñao, A. (2005). Tiempos familiares, Tiempos escolares (trabajo infantil y asistencia escolar en España durante la segunda mitad del siglo XIX y el primer tercio del siglo XX). História da Educação, 17, 33-50.

Vuillermet, F. A. (1925). La juventud y los deportes. Madrid: Ed. Voluntad.

Zulueta, J. (1903, septiembre 22). Culto a la acción. El progreso de Asturias, pp. 1-2. 